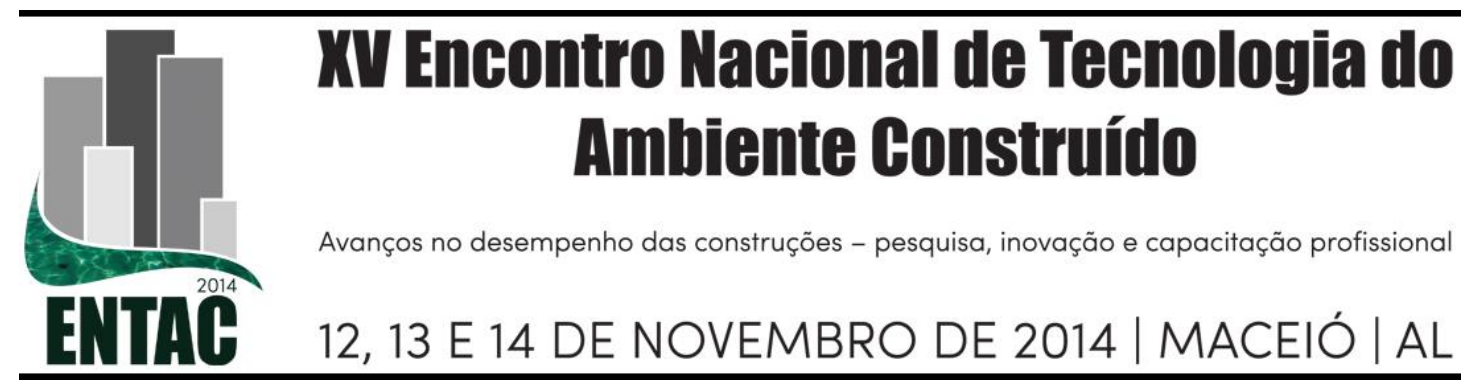

\title{
JOGO DIDÁTICO PARA TORNAR PRÁTICO O USO DAS ATIVIDADES QUE CONTRIBUEM PARA A MELHORIA DE PROCESSO: ELEVAÇÃO DA ALVENARIA ESTRUTURAL
}

\author{
MESQUITA, Victor Felix de (1); RAMOS SANTOS, Paulo Ricardo (2); \\ LUDUVICE NETO, Pedro (3); NASCIMENTO, Rafael da Silva (4); SANTOS, \\ Débora de Gois (5) \\ (1) Universidade Federal de Sergipe, (85) 9675-0608, e-mail: \\ victorfmesquita@yahoo.com.br (2) Universidade Federal de Sergipe, e-mail: \\ paulo_ricardo.rs@ hotmail.com (3) Universidade Federal de Sergipe, e-mail: \\ pedroluduvice@gmail.com (4) Universidade Federal de Sergipe, e-mail: \\ rafaelsn_10@ hotmail.com (5) Universidade Federal de Sergipe, e-mail: \\ deboragois@yahoo.com.br
}

\begin{abstract}
RESUMO
As boas práticas buscam eliminar fatores que gerem interrupções nos processos que ocorrem nos canteiros de obras. O objetivo desta pesquisa foi desenvolver um jogo didático que auxilie os gerentes de obras no uso das boas práticas no processo construtivo de elevação da alvenaria estrutural, estimulando a continuidade dos fluxos de produção e eliminando perdas. A metodologia envolveu os procedimentos necessários para o desenvolvimento e validação de jogo didático proposto, com realização de estudo exploratório; elaboração de lista de boas práticas; elaboração, validação e aplicação de checklist; desenvolvimento de jogo didático e sua validação através da aplicação em forma de dinâmica de grupo, primeiramente com professores e alunos de iniciação científica e, posteriormente, com gerentes de três dos seis canteiros de obras em que se desenvolveram os estudos. Como resultado, constatou-se que a negligência da maioria dessas atividades poderia resultar na ocorrência de perdas por making-do e, consequentemente, em retrabalhos; os gerentes utilizam boas práticas no seu dia a dia e o jogo de simulação confirmou as informações observadas em campo e proporcionou uma visão geral do processo pelos gerentes. Conclui-se que o jogo didático é uma ferramenta que pode ser utilizada para treinar profissionais na identificação de pontos fortes e frágeis relacionados com as atividades gerenciais tanto para processo construtivo estudado como em outros processos.
\end{abstract}

Palavras-chave: Boas práticas, Atividades facilitadoras, Construção enxuta, Jogos e simulações.

\begin{abstract}
Best practices seek to eliminate factors that create interruptions in processes and that occur at construction sites. The objective of this research was to develop a didactic game that helps managers to make practical the use of best practices in structural masonry construction process, to stimulate flow production continuity and to eliminate wastes. The methodology involves the procedures required to development and validation of proposed tool. For this, the following tasks were carried out: exploratory study, preparation of a best practices list, development, validation and application of a checklist; development of didactic game and its validation by the application in a group dynamics, primarily with professors and scientific initiation students, and later with managers of three of the six construction sites researched. As a result it was found that the neglect of most of these activities could result in the occurrence of making-do and consequently in rework; the managers use best practices in their daily and.
\end{abstract}


the game confirmed the information observed in the field and provided an overview of the process by managers. The conclusion is that the game is a teaching tool that can be used to train professionals in the identification of strengths and weaknesses related to management activities not only in construction process of structural masonry elevation, but also in other processes.

Keywords: Best practices, Extra-planning activities, Lean construction, Games and simulations.

\section{INTRODUÇÃOO}

Na busca pela eliminação ou redução de atividades que não agregam valor ao produto final na construção civil, inserem-se as atividades que contribuem para a melhoria dos processos construtivos, identificadas na literatura como boas práticas, que buscam eliminar fatores que gerem, direta ou indiretamente, interrupções nos processos que ocorrem nos canteiros de obras.

A prática dessas atividades evita a ocorrência de perdas. Ohno (1997) propõe sete categorias de perdas, são elas: superprodução; transporte, processamento em si, estoque, fabricação de produtos defeituosos, movimentação e espera. Além dessas categorias, Koskela (2004) definiu o making-do como o oitavo tipo de perda. Situação na qual a tarefa começa antes que todos os recursos necessários estejam disponíveis para que o trabalho inicie ou continue até seu término.

Para Oglesby, Parker e Howell (1989), Alves (2000), Bernardes (2001), Machado (2003) e Santos (2004), as atividades que contribuem para a melhoria dos sistemas produtivos na construção civil podem ser encontradas sob diversas denominações, desde as mais genéricas às mais específicas, como, por exemplo: boas práticas, atividades facilitadoras, antecipações, antecipações gerenciais, ações gerenciais, entre outras.

Baseado na referida literatura, para este estudo, o termo "atividades que contribuem para a melhoria dos processos construtivos" representa a forma mais genérica de denominação para as "boas práticas", que visem eliminar ou reduzir, direta ou indiretamente, os fatores que gerem interrupções nos diversos processos e fluxos de produção que ocorrem dentro dos canteiros de obras.

Assim, os jogos podem ser utilizados como ferramentas lean para evitar a ocorrência de descontinuidades nos processos produtivos de forma lúdica e interativa entre os gerentes de obras, estimulando o fluxo da informação e o processo de difusão do conhecimento. Os jogos são uma estratégia de aprender a fazer através da simulação de uma situação real, buscando integrar a teoria com a prática (SANTOS; LOVATO, 2007).

O objetivo geral desta pesquisa consistiu em desenvolver um jogo didático que auxiliasse os gerentes de obras no uso das atividades que contribuem para a melhoria do processo construtivo de elevação da alvenaria estrutural.

\section{APRENDIZAGEM POR JOGOS E SIMULAÇÕES}

De acordo com Romanel (2009), a busca por novas formas de aprendizagem é uma característica dos empreendimentos inovadores e atentos às mudanças e nuances do mercado. Desde o final dos anos 1950 e com mais frequência a partir dos anos 1990, os jogos têm sido aplicados em salas de aula e também nas organizações, como alternativa aos métodos tradicionais de aprendizagem.

Lopes (2004) afirma que no jogo as pessoas são convidadas a participar de um empreendimento simulado, em que desafios e problemas são lançados. Elas mesmas constroem seus padrões de organização e decisão, trazendo à tona suas habilidades e dificuldades. Assim, ao término do processo de simulação, as pessoas relatem seus 
sentimentos, reações e emoções durante a vivência simulada. A partir dessas conclusões, os jogadores já conseguem estabelecer comparações e analogias da atividade simulada com a realidade empresarial.

Segundo Gramigna (2007), na empresa, em geral, o funcionário prefere não se arriscar e acomodar-se num processo padronizado de atitudes e postura, ao contrário do que acontece com a simulação através de jogos, em que o treinando pode tomar decisões, estabelecer metas, planejar suas situações sem se preocupar com as consequências. Para Braga et al. (2007), os principais objetivos trabalhados pelos jogos incluem: trabalhar a ansiedade, rever limites, reduzir a descrença na auto capacidade de realização, desenvolver a autonomia, aumentar a atenção e concentração, desenvolver antecipação e estratégia e ampliar o raciocínio lógico.

Tsao et al. (2013) relataram formas de como melhor repassar os conceitos, métodos e técnicas da construção enxuta para estudantes acadêmicos. O referido estudo concluiu que a aprendizagem por jogos e simulações foi a forma mais eficaz, já que os seus alunos desenvolveram um entendimento teórico mais sólido dos princípios lean, bem como das suas aplicações na Indústria da Construção Civil. Para Golzarpoor e González (2013), os jogos e simulações podem ser considerados como uma estratégia de pesquisa no caso da construção civil, por proporcionar robustez ao estudo e permitir a sua análise detalhada ao final do processo de aplicação.

\section{METODOLOGIA}

\subsection{Fases da pesquisa}

A estratégia de pesquisa foi o constructive research (pesquisa construtiva) ou design science, o qual pode ser conduzido como múltiplos estudos de caso (Lukka, 2003; Holmström et al., 2009) ou pesquisa-ação (Holmström et al., 2009). O delineamento deste trabalho foi dividido em duas fases. A primeira formada pelo referencial teórico e a segunda composta por cinco etapas, compreendendo os grupos Compreensão, Estruturação e Consolidação.

Na etapa 1, fase Compreensão, foi realizado estudo exploratório, para a compreensão do processo executivo de elevação da alvenaria estrutural e também para o entendimento do modelo adotado. Neste estudo exploratório, foram realizadas observações diretas, registros fotográficos, entrevistas não estruturadas, reuniões com os engenheiros da gestão da obra e do planejamento (brainstorming), consultas a projetos e a normas técnicas, bem como análise do procedimento operacional da empresa para o processo de elevação de alvenaria. Por fim, foi possível elaborar um fluxograma para o processo pesquisado, com a inserção e identificação das boas práticas.

$\mathrm{Na}$ etapa 2, fase Estruturação, foi elaborada uma lista de boas práticas, com base nas atividades encontradas no fluxograma da etapa anterior, na literatura nacional, em procedimentos executivos e normas técnicas para a alvenaria estrutural.

Esta lista foi formatada como um quadro com as seguintes colunas: "item", "frequência (\%) do item", "atividade" (boa prática), "descrição", "causas" (restrições caso a atividade não seja posta em prática), "vantagem" (caso a atividade seja utilizada), "princípio(s) lean relacionado(s)" (Koskela, 1992), "categoria(s) de perda" (Shingo, 1996; Koskela, 2004), "se não utilizar a atividade o trabalho pode ser interrompido?", "categoria de atividade facilitadora" (Santos, 2004) (usada também para as boas práticas), "nível hierárquico do planejamento" e "fonte de pesquisa". 
Partiu-se, então, para a etapa 3, fase Estruturação. Foi necessário identificar quais boas práticas listadas (63 atividades) deveriam ser consideradas como AF's, ao aplicar o questionamento: Se não utilizar a boa prática, o trabalho pode ser interrompido? Caso a resposta fosse afirmativa ( $\mathrm{sim}$ ), a boa prática seria considerada atividade facilitadora.

Para a seleção das AF's, utilizou-se como ferramenta de apoio ao planejamento o Diagrama de Ishikawa, tornando possível a correlação com os níveis hierárquicos de decisão. Já para a seleção das demais boas práticas listadas foi levada em consideração a frequência das atividades. O resultado foi um checklist a ser aplicado com gerentes de obras em canteiros de obras de alvenaria estrutural contendo 31 atividades.

Como estratégia de estruturação do checklist, para cada categoria foi montado um quadro contendo "Número do item", "Atividade" e "Objetivo da boa prática". Ressaltase que a informação "Objetivo da boa prática" serviu somente para efeitos de validação do checklist, sendo este suprimido durante a fase de aplicação. Como opções de respostas para os gerentes de obras foram estabelecidas as opções "Nenhuma importância", "Pouco importante", "Indiferente", "Importante" e "Muito importante", para que cada atividade fosse posta em prática pelos gerentes.

Em seguida, o questionário foi submetido para validação de um especialista. Esta ação foi determinante para a utilização do termo "atividades que contribuem para a melhoria do processo construtivo" ou "boas práticas".

Ainda na fase de Estruturação, etapa 4, para a aplicação do checklist foram selecionados seis empreendimentos com elevação de alvenaria em andamento (Obras A, B, C, D, E e F), cada um pertencente a uma empresa construtora diferente. Dessa forma, foi possível obter pontos de vista diversos, aumentando a confiabilidade do estudo, já que este se baseou primordialmente no conhecimento tácito dos gestores de obras.

$\mathrm{Na}$ etapa 5 (fase Consolidação), que corresponde ao desenvolvimento, à validação e à aplicação do jogo didático, foi possível desenvolver um jogo didático lúdico, denominado "Estimulando Práticas - Alvenaria Estrutural", para a simulação do problema de pesquisa em questão. Essa ferramenta foi validada primeiramente com pesquisadores e, posteriormente, com gerentes de obras de três das seis empresas investigadas. Foram convidados os entrevistados e seus superiores. Ao final da dinâmica de grupo, os gestores foram convidados a analisar as contribuições do jogo para a solução de problemas de obra e levantar questionamentos para trabalhos futuros.

\subsection{Proposta de aplicação do jogo "Estimulando Práticas - Alvenaria Estrutural"}

O jogo contribui para a aplicação dos conceitos da construção enxuta na medida em que sugere a realização de um processo construtivo visando a continuidade do fluxo de produção, por meio da introdução de melhoria contínua ao processo e a eliminação de atividades que não agregam valor para o produto final. $\mathrm{O}$ simulador auxilia ainda na prevenção contra a ocorrência de perdas por making-do, já que sua aplicação sugere que todos os recursos estejam disponíveis quando solicitados, evitando improvisações e, consequentemente, retrabalhos no processo.

O jogo propõe uma dinâmica, em que os jogadores podem assimilar os preceitos da mentalidade enxuta e, posteriormente, disseminá-los. A dinâmica pode ser aplicada com qualquer quantidade de jogadores (individual ou em grupo). Cada equipe dispõe de um kit (Figura 1), composto por manual do jogo, 02 (duas) cópias do fluxograma para o processo de elevação da alvenaria estrutural, 37 (trinta e sete) setas adesivas com providências, caneta marca-texto, tesoura e régua de plástico e fotos adesivas diversas. 
O fluxograma que funciona como o tabuleiro do jogo, representa o passo a passo de um processo de elevação da alvenaria estrutural, desde a entrega da laje pela equipe anterior e a marcação da primeira fiada até a execução e o grauteamento da fiada de respaldo.

\section{Figura 1 - Componentes do Kit}

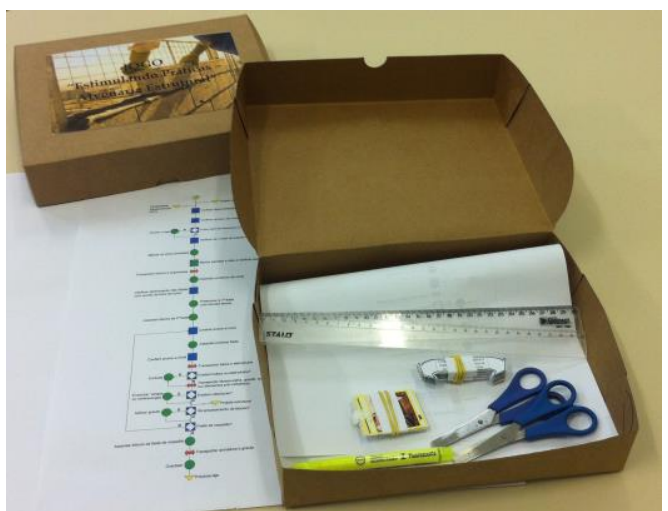

Fonte: Registrado pelo autor

As setas (Figura 2) contêm providências a serem tomadas diante da simulação de um processo de elevação da alvenaria estrutural. Estas foram identificadas através de quatro cores distintas, sendo que duas correspondem a pontos positivos e duas a pontos frágeis. Os pontos positivos tratam-se das Boas Práticas (BP) (verdes) (pontua-se positivamente) e das Atividades Facilitadoras (AF) (azuis) (pontuação máxima para o item), já os pontos frágeis correspondem às Atividades Falhas Leves (AL) (preto) (forma tardia ou o não atendimento a uma BP) e às Atividades Falhas Graves (AG) (laranja) (forma tardia ou o não atendimento a uma $\mathrm{AF}$ ou ainda o não cumprimento de itens de normas, logo pontuação máxima negativa). As setas utilizadas são duplas, com as duas extremidades curvas, para permitir que os participantes possam posicioná-las livremente no fluxograma em ambos os lados.

\section{Figura 2 - Exemplos de providências utilizadas no jogo}

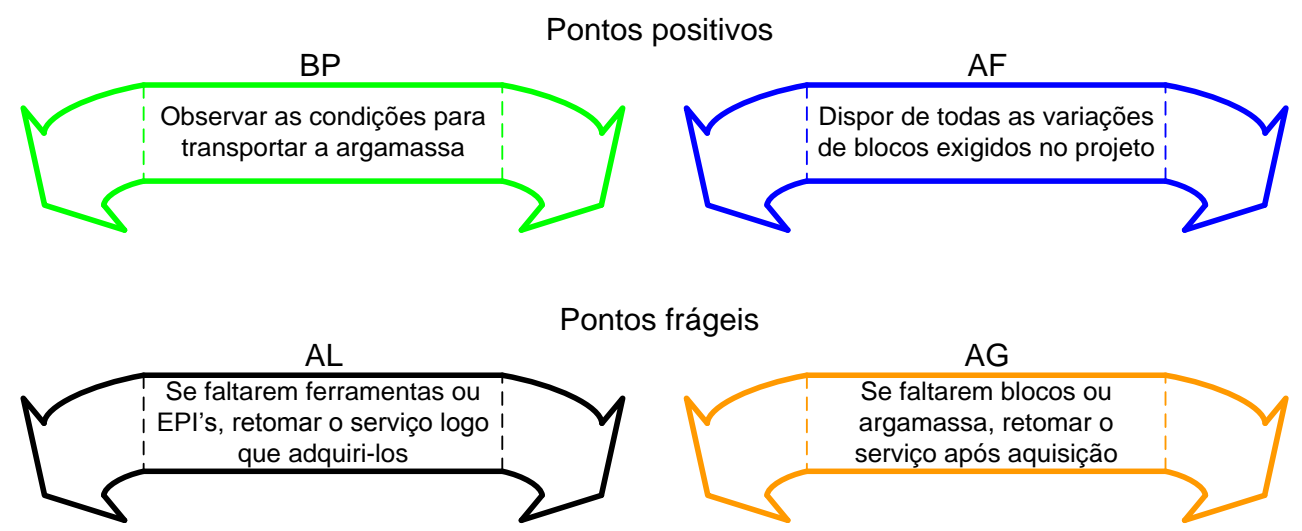

Fonte: Elaborado pelo autor

A utilização de fotos no jogo proporciona um caráter lúdico e interativo entre os participantes, relacionando a simulação com a realidade da obra. Portanto, o gerente que associar corretamente a foto à providência, deve receber um bônus extra.

Assim, para simular a execução de um processo de elevação de alvenaria estrutural sem interrupções, o ministrante deve apresentar as instruções aos jogadores, que devem 
utilizar as setas e o marcador de texto no fluxograma. Se achar necessário, o gerente deve posicionar a seta ao lado daquela atividade que não deve ser interrompida. Após decidir a posição, deve recortar adequadamente a seta dupla e colá-la no fluxograma.

Caso o gerente já identifique uma providência existente dentro do próprio fluxograma, deve destacá-la com o auxílio da caneta marca-texto e da régua. No total, o gerente tem à sua disposição 37 atividades (como aquelas mencionadas na Figura 2), devendo utilizar aquelas que ele julgar necessárias. Após esse procedimento, os participantes, caso desejem, podem ainda inserir uma ou mais fotos ao lado daquela(s) atividade(s) que acharem necessário. Recomenda-se a utilização de 40 (quarenta) minutos para a conclusão do jogo. A Figura 3 apresenta os tipos de providências, as pontuações individuais dessas atividades, bem como as pontuações máximas.

Figura 3 - Tabela com pontuações máximas alcançáveis

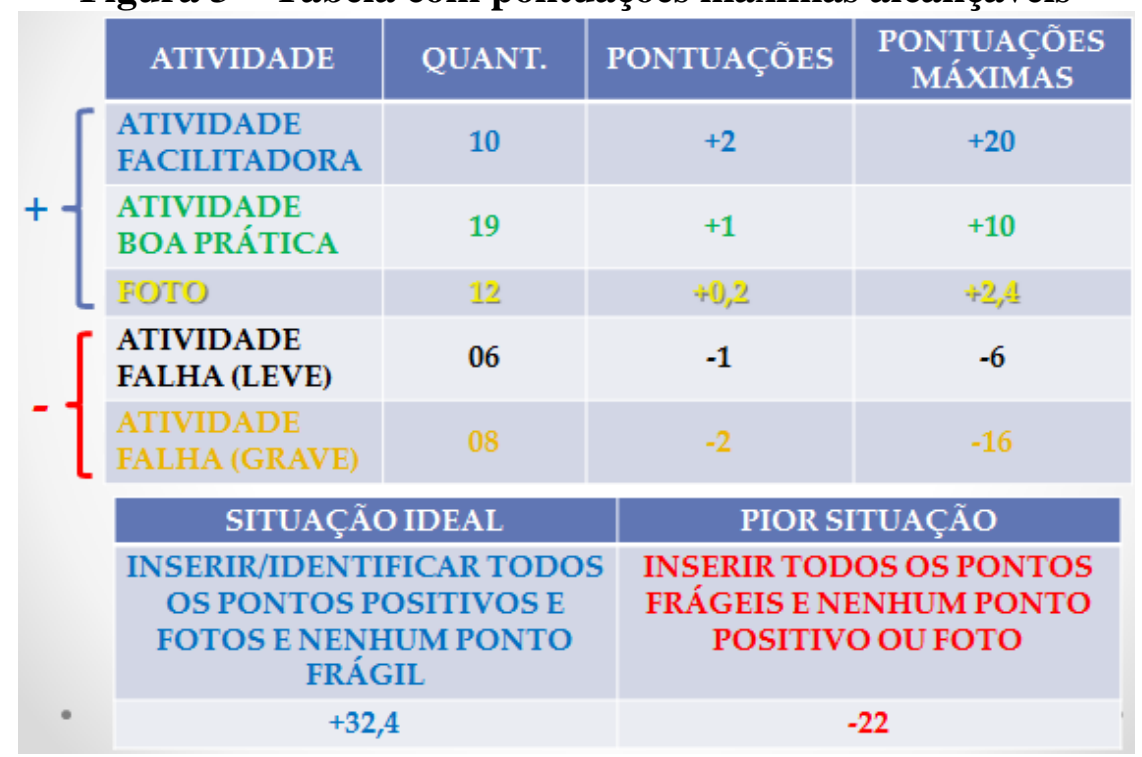

Fonte: Elaborado pelo autor

Após a aplicação da dinâmica, são discutidos os pontos frágeis do jogo, principalmente aqueles que foram utilizados pelos participantes. Abre-se então uma mesa de discussões para que sejam debatidas as estratégias utilizadas e quais foram as principais contribuições para o conhecimento dos participantes, buscando formas de utilizar, no dia a dia, as atividades que contribuem para a melhoria do processo de elevação da alvenaria estrutural.

\section{RESULTADOS}

\subsection{Aplicação do checklist}

A análise das respostas do checklist fornecidas pelos gerentes não foi realizada isoladamente, mas em conjunto com aspectos observados durante as visitas realizadas nas obras. Em termos da estatística geral das respostas, infere-se que $82,80 \%$ dos gerentes entrevistados consideram como "importante" ou "muito importante" a utilização das boas práticas no processo de elevação da alvenaria estrutural, significando que, independente da utilização dessas atividades no dia a dia, os gestores reconhecem que a sua adoção reduz a ocorrência de perdas e pode trazer benefícios para a continuidade do fluxo. Já a adoção das atividades consideradas como "nenhuma importância", "pouco importante" ou "indiferente", totalizaram 17,20\% do total da 
escala de importância, o que pode indicar a existência de pontos de alerta no processo de produção e estes merecem atenção (Figura 4).

Figura 4 - Gráfico das porcentagens totais por categoria

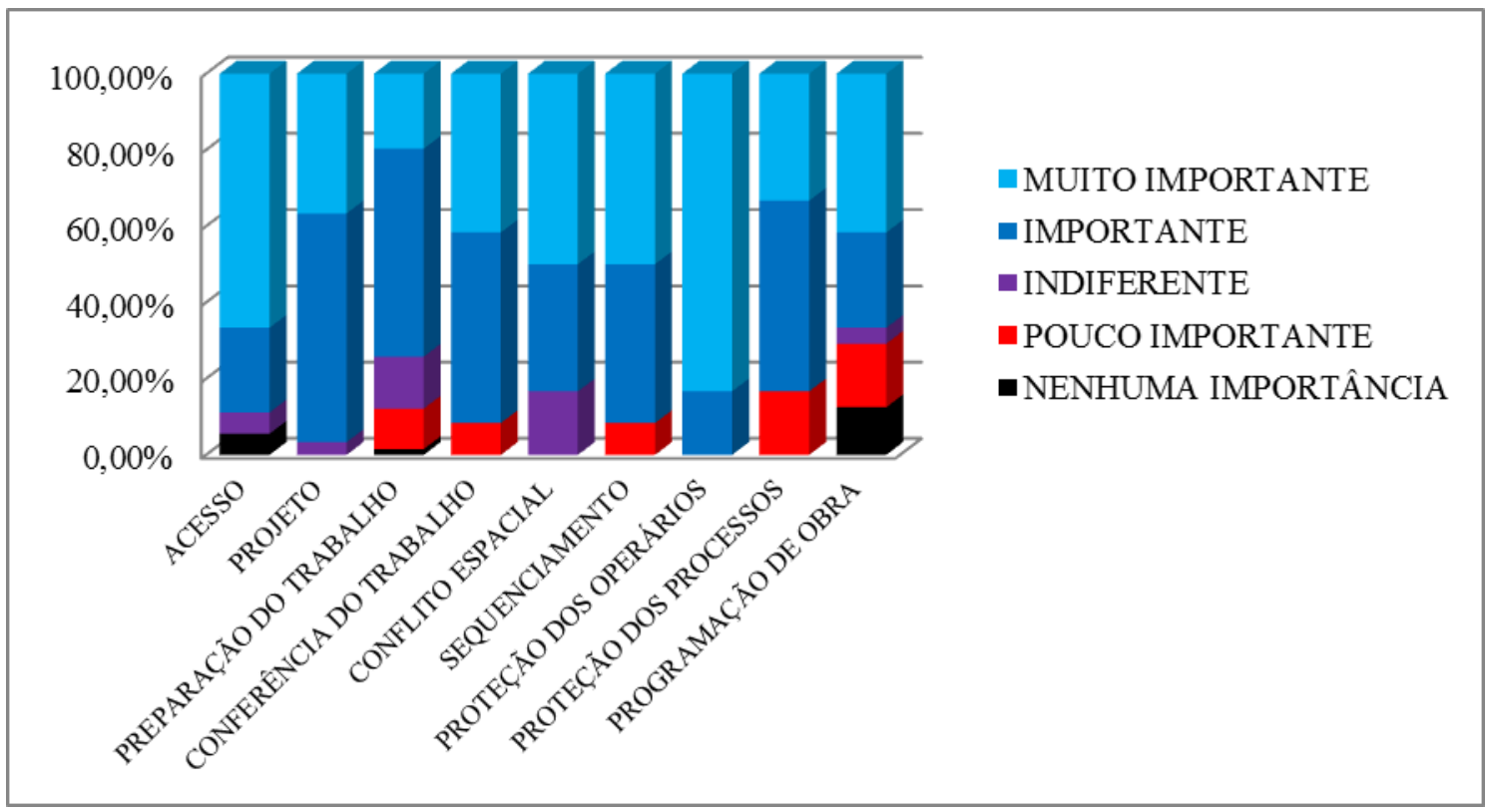

Fonte: Elaborado pelo autor

Observa-se que as quatro categorias que atingiram maiores porcentagens de atividades consideradas "importantes" ou "muito importantes" foram, em ordem decrescente, "Proteção dos Operários" (100\%), "Projeto" (96,67\%) e, com a mesma porcentagem, as categorias "Conferência do Trabalho" (91,67\%) e "Sequenciamento" (91,67\%). Entende-se, que na visão dos respondentes, estas seriam as categorias onde as perdas estariam mais visíveis.

\subsection{Aplicação do jogo "Estimulando Práticas - Alvenaria Estrutural"}

O processo de aplicação do jogo foi realizado com quatro engenheiros pertencentes a três empresas distintas. Cada equipe foi constituída por dois engenheiros, sendo um de cada empresa presente e foi assistida por uma pessoa da equipe de apoio, os quais sanaram as dúvidas que porventura surgissem. Os demais membros da equipe de apoio prestaram auxílio na montagem dos kits, organização das fotos, coleta de registros fotográficos e filmagem da dinâmica. A equipe de apoio contou com o suporte de uma professora mestre em psicologia, a qual realizou uma análise comportamental dos participantes e da forma de aplicação da dinâmica. Ao final do processo de aplicação, elaborou-se o quadro da Figura 5.

Alertou-se aos gerentes sobre os pontos de fragilidade inseridos no fluxograma e foram explicados os motivos pelos quais aqueles poderiam ser considerados como pontos de vulnerabilidade para a continuidade do fluxo de produção. Observou-se ainda que os três pontos frágeis adotados por cada uma das equipes foram exatamente os mesmos: "Familiarizar-se com os projetos para não haver interrupção ao consulta-los (FG)"; "Refazer a parede quando detectados pontos fora de nível e/ou prumo (FL)"; e "Utilizar como referência o ponto mais alto da laje se esta não estiver nivelada (FL)". 
Figura 5 - Resultados do jogo aplicado com gerentes de obras

\begin{tabular}{|c|c|c|c|c|c|c|}
\hline \multirow{2}{*}{ EQUIPE } & \multicolumn{2}{|c|}{ PONTOS POSITIVOS } & FOTOS & \multicolumn{2}{|c|}{ PONTOS FRÁGEIS } & \multirow{2}{*}{$\begin{array}{c}\text { ATIVIDADE } \\
\text { FACILITADORA }\end{array}$} \\
BOA PRÁTICA & FOTOS & $\begin{array}{c}\text { ATIVIDADE } \\
\text { FALHA (LEVE) }\end{array}$ & $\begin{array}{c}\text { ATIVIDADE } \\
\text { FALHA } \\
\text { (GRAVE) }\end{array}$ & TOTAL \\
\hline A & 6 & 15 & 11 & 2 & 1 & 25,20 \\
\hline B & 7 & 12 & 9 & 2 & 1 & 23,80 \\
\hline
\end{tabular}

Fonte: Elaborado pelo autor

As três falhas cometidas condizem com a realidade observada em alguns canteiros de obras, corroborando com informações coletadas durante as visitas de campo. A gestora da obra E, por exemplo, na fase de aplicação do checklist, mostrou-se indiferente à consulta dos projetos de modulação durante o processo de elevação da alvenaria. A opinião da gestora, que estava presente na dinâmica, foi novamente revelada na fase de aplicação do jogo simulativo.

As outras duas FL utilizadas remetem a ocorrências de retrabalhos. A informação pode ser confirmada através de alguns casos de retrabalho que foram observados e relatados nos canteiros pesquisados durante a fase de coleta das informações.

Observa-se que a equipe A utilizou mais atividades Boas Práticas e fotos do que a equipe B. Dos pontos positivos identificáveis no fluxograma (intrínsecos ao processo), o grupo A identificou uma AF e o $\mathrm{B}$ uma $\mathrm{AF}$ e uma BP. No geral, a primeira equipe adotou mais pontos positivos e fotos no seu fluxograma. As duas equipes inseriram poucos pontos de fragilidade. Pelo somatório dos pontos, o grupo A atingiu um melhor desempenho. Cabe, então, uma análise da estratégia de ação utilizada pelas equipes e a observação dos fluxogramas finais montados.

A equipe A, da qual fazia parte o engenheiro de planejamento, definiu previamente as atividades predecessoras e utilizou como estratégia separar todas as providências por cor, espalhando-as sobre a mesa e estabelecendo o grau de importância de cada grupo de providências. Dessa forma, a equipe foi adotando aquelas providências à medida que as julgasse como necessárias e relevantes para o processo. Já a equipe B também definiu as atividades predecessoras, porém, não houve critérios para a seleção das providências e nem uma análise prévia destas. Os gerentes simplesmente juntaram todas as atividades aleatoriamente e iam olhando uma a uma para, então, inserir no fluxograma na posição que definissem como correta.

Ao observar as Figuras 6 (a) e 6 (b), as informações anteriores podem ser confirmadas. O fluxograma da equipe A encontra-se visualmente mais organizado e com as atividades melhor posicionadas e precisas quanto à localização e ação no tempo exato. Portanto, a Equipe A agiu de forma estratégica e a B de forma operacional, apesar dos dois grupos terem considerado a adoção de medidas para que o processo não parasse por ausência de recursos, dificultando a ocorrência de making-do.

Quando analisados somente os critérios de pontuação, constatou-se que as equipes A e B obtiveram, respectivamente, 25,20 e 23,80 como pontuações finais, o que representa, nesta mesma ordem, 77,78\% e 73,46\% da situação ideal para o jogo (conforme Figura 3). Na prática, isto pode significar que, independente da quantidade de pontos frágeis existentes nos processos produtivos, os gerentes adotam pontos positivos e preocupamse com a continuidade dos fluxos no canteiro de obras. 
Figura 61 - Fluxogramas elaborados pelas equipes na aplicação com os gerentes

(a) Equipe A

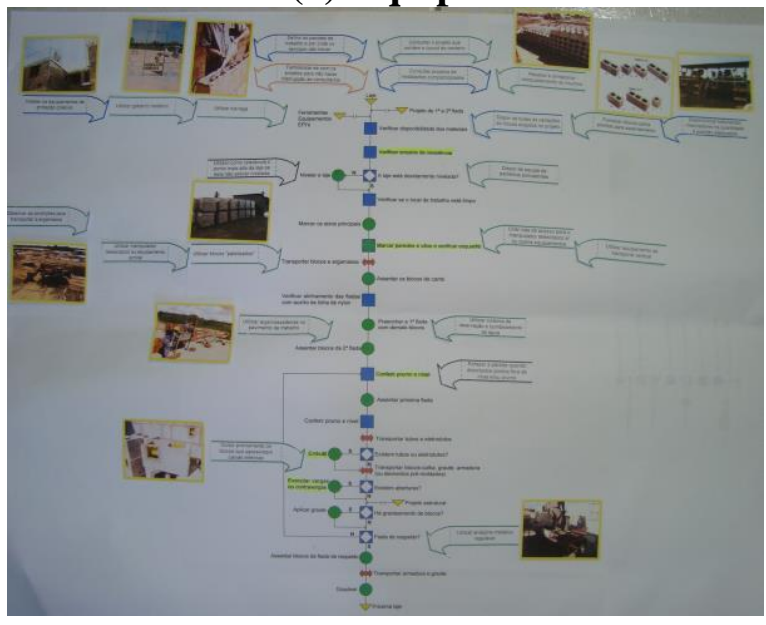

Fonte: Registradas pela equipe de apoio. (b) Equipe B

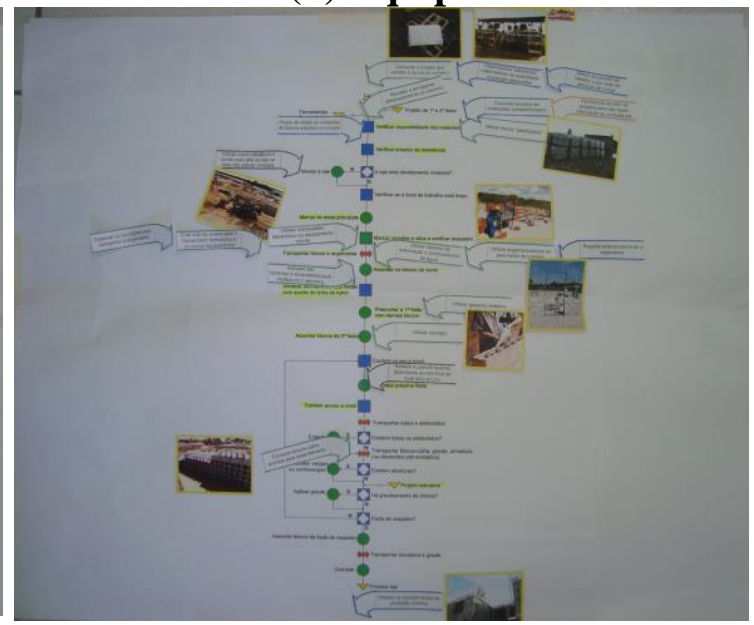

\section{CONSIDERAÇÕES FINAIS}

As informações contidas neste artigo foram extraídas a partir de uma pesquisa de dissertação de mestrado que buscou desenvolver uma ferramenta prática que auxiliasse os engenheiros de obras que trabalham no gerenciamento do processo construtivo de elevação da alvenaria estrutural.

A dinâmica traduz o que acontece no dia a dia dos gestores e as providências representam a maneira com que os gerentes tentam contornar os problemas ocorridos durante a execução do processo. As atividades destacadas pelos participantes, com o auxílio da caneta marca-texto, representam as BP's e AF's que contribuem para evitar interrupções e as quais a empresa já utiliza. Logo, estas já estão no seu procedimento operacional e, teoricamente, já fazem parte da rotina do gestor.

Já as informações contidas nas setas (providências) devem ser constantemente lembradas, na tentativa de busca-las a partir de iniciativas da empresa e do gestor. Quando estas são negligenciadas, acontecem as interrupções tão frequentes nas obras e, como já se tornaram uma rotina, os gerentes acabam achando normal a sua existência. É nesse ponto que a utilização de recursos como o jogo simulativo pode ser útil.

O processo de aplicação do jogo remete, ainda, à reflexão de que as pessoas envolvidas no processo de produção podem estar pensando e agindo como verdadeiros gestores ou como operários da construção. No último caso, o conceito lean sempre estará mais distante e será mais difícil o incremento na produtividade e qualidade, bem como a satisfação dos clientes. Por outro lado, mesmo agindo de forma operacional, a aplicação da dinâmica mostrou que as "atividades que contribuem para a melhoria dos processos produtivos" são atividades simples e podem ser utilizadas, no dia a dia, mesmo pelas pessoas que não detêm o conhecimento dos conceitos da construção enxuta.

\section{REFERÊNCIAS}

ALVES, T. C. L. Diretrizes para a Gestão dos Fluxos Físicos em Canteiros de Obras: Proposta Baseada em Estudo de Caso. Porto Alegre, 2000. Dissertação (Mestrado) Programa de Pós-Graduação em Engenharia Civil, Universidade Federal do Rio Grande do Sul. Porto Alegre. 2000. 
BERNARDES, M. M. S. Desenvolvimento de um modelo de planejamento e controle da produção para micro e pequenas empresas da construção. 2001. Tese (Doutorado) Programa de Pós-Graduação em Engenharia Civil da Universidade Federal do Rio Grande do Sul. Porto Alegre. 2001.

BRAGA, A. J. et al. Uso dos jogos didáticos em sala de aula. 10 f. Trabalho acadêmico (Linguística Aplicada), Curso de Letras, Universidade Luterana do Brasil, Guaíba, 2007.

GOLZARPOOR, H.; GONZÁLEZ, V. A green-lean Simulation Model for Assessing Environmental and Production Waste in Construction. In: CONFERENCE OF THE INTERNATIONAL GROUP FOR LEAN CONSTRUCTION, 21., 2013, Fortaleza. Proceedings... Fortaleza, 2013, 10p.

GRAMIGNA, M. R. Jogos de Empresa. São Paulo: Pearson, 2007, $2^{a}$ ed., 180p.

HOLMSTROM, J.; KETOKIVI, M.; HAMERI, A. Bridging Practice and Theory: A Design Science Approach, Decision Sciences, v. 40, n. 1, 2009.

KOSKELA, L. Application of the new production philosophy to construction. Technical Report $\mathbf{n}^{\mathbf{*}}$. 72. Center of Integrated Facility Engineering. Department of Civil Engineering. Standford University, 1992, $72 \mathrm{p}$.

KOSKELA, L. Making-do - The Eight Category of waste. In: CONFERENCE OF THE INTERNATIONAL GROUP FOR LEAN CONSTRUCTION, 12., 2004, Dinamarca. Proceedings... Dinamarca, 2004.

LOPES, V. M. D. L. Jogos e Técnicas Vivenciais. Joinville: SENAI, 2004. 98p.

LUKKA, K. The constructive research approach. In: Case Study research in logistics (edited by Ojala, L.; Hilmola,O-P.). Series B1. P.83-101. Turku: Turku School of Economics and Business Administration, 2003.

MACHADO, R. L. A sistematização de antecipações gerenciais no planejamento da produção de sistemas da construção civil. 2003. Tese (Doutorado) - Programa de Pósgraduação em Engenharia de Produção da Universidade Federal de Santa Catarina. Florianópolis. 2003.

OGLESBY, C. H.; PARKER, H. W.; HOWELl, G. A. Productivity improvement in construction. McGRAW-HILL Series Engineering and Project Management, 1989, 588p.

OHNO, T. O Sistema Toyota de Produção: além da produção em larga escala. Porto Alegre: Bookman, 1997. 149p.

ROMANEL. F. B. Jogo "Desafiando a Produção": Uma Estratégia para a Disseminação dos Conceitos da Construção Enxuta entre Operários da Construção Civil. 2009. Dissertação (Mestrado) - Programa de Pós-Graduação em Construção Civil da Universidade Federal do Paraná. Curitiba. 2009.

SANTOS, D. G. Modelo de Gestão de Processos na Construção Civil para Identificação de Atividades Facilitadoras. 2004. Tese (Doutorado) - Programa de Pós-Graduação em Engenharia de Produção da Universidade Federal de Santa Catarina. Florianópolis. 2004.

SANTOS, M. R. G. F.; LOVATO, S. Os Jogos de Empresa como Recurso Didático na Formação de Administradores. Revista Novas Tecnologias na Educação, v. 5, p., 2007.

SHINGO, S. O Sistema Toyota de Produção do ponto de vista da engenharia de produção. Porto Alegre: Artes Médicas, 1996. 291p.

TSAO et al. Teaching Lean Construction -Perspectives On Theory And Practice. In: CONFERENCE OF THE INTERNATIONAL GROUP FOR LEAN CONSTRUCTION, 21., 2013, Fortaleza. Proceedings... Fortaleza, 2013, 10p. 